\title{
Distribución de Receptores de Estrógenos Beta en el Ovario de Ovejas Prepúberes
}

\author{
Beta Estrogen Receptors Distribution in the Ovary of Ewe Lambs
}

\author{
Adriana Vasconcellos C.,"**; Marco Paredes H..; Cecilia Aguilar G.** \& Javiera Navarrete V.*
}

VASCONCEllos, C. A.; PAREDES, H. M.; AGUILAR, G. C. \& NAVARRETE, V. J. Distribución de receptores de estrógenos beta en el ovario de ovejas prepúberes. Int. J. Morphol., 33(1):388-392, 2015.

RESUMEN: Las hormonas esteroidales tienen un papel esencial en la fisiología reproductiva, actúan en el ovario estableciendo comunicación entre este y la glándula hipofisiaria y también en forma paracrina como reguladores locales. Se ha descrito expresión de receptores de estrógeno a nivel de ovarios fetales, neonatales y adulto, siendo necesario determinar cuales son los tipos celulares que expresan estos receptores. El ovario ovino es estereogénico activo desde la etapa fetal y por lo tanto los esteroides desempeñan un importante papel en el desarrollo gonadal. La regulación del crecimiento folicular está relacionado a varios factores por un lado la secreción de gonadotropinas por la hipófisis interviene durante el desarrollo folicular tardío, existiendo evidencias de una acción intraovárica directa de los estrógenos, en la regulación del crecimiento folicular temprano. Nuestro objetivo fue, evaluar la expresión y distribución de receptores de estrógeno $\beta$ en las distintas poblaciones celulares del ovario de la oveja prepúber.

PALABRAS CLAVE: Oveja; Ovario; Receptor de estrógeno; Raza Araucana.

\section{INTRODUCCIÓN}

La función ovárica en mamíferos es regulada por las hormonas esteroidales. Ellas desempeñan un importante papel en la comunicación entre el ovario y la glándula pituitaria actuando también en forma paracrina, intraóvarica, como reguladores locales (Evanns, 2003). Sus funciones pueden diferir entre las distintas especies

En muchas especies el ovario en desarrollo es esteoideogénico activo (Mauleon et al., 1977; Juengel et al., 2006). En monos y ovejas, la exposición prenatal y perinatal a los esteroides durante el desarrollo gonadal y la formación folicular conduce a una alteración de la morfología ovárica con un gran número de folículos quísticos (Koering et al., 1994). Por lo tanto en varias especies los esteroides desempeñan un importante papel destacado durante el desarrollo gonadal.

La regulación del crecimiento folicular está relacionada a varios factores, por un lado a las hormonas secretadas por la hipófisis tales como las gonadotropinas que actúan durante el desarrollo folicular tardío, mientras que hay evidencia de una acción directa intraovárica desempeñada, es- pecialmente por los estrógenos y andrógenos, en la regulación del crecimiento folicular temprano (Koering et al.; Drummond et al., 2002; Britt et al., 2004).

Se han descrito en el ovario de ovejas células esteroidogenicas activas ubicadas en la unión corticomedular con características de células de pregranulosa que tendrían la capacidad de modular la dinámica folicular (Juengel et al., 2002; Sawyer et al., 2002). Diversos estudios han observado expresión de receptores de estrógeno alfa, la isoforma beta y receptores de andrógenos a nivel de los folículos, del epitelio de revestimiento superficial y en el estroma del ovario fetal, neonatal y adulto (Meikle et al., 2001; Juengel et al., 2006). La mayor parte de la acciones de los estrógenos en los ovarios son mediadas por receptores beta (RE- $\beta$ ) (Juengel et al., 2006). Se ha demostrado que en la hembra ovina las hormonas esteroidales regulan la función de diferentes tipos celulares durante el desarrollo, la formación de folículos y el crecimiento folicular temprano (Drummond et al.), estimulan la proliferación de las células de la granulosa, aumenta los niveles de receptores de gonadotropina y la capacidad de respuesta de las células de

\footnotetext{
* LINBA, Laboratorio de Investigación en Biotecnología Animal, Universidad de La Frontera, Temuco, Chile.

** CEBIOR, Centro Biotecnológico de la Reproducción, Universidad de La Frontera, Temuco, Chile.
} 
la granulosa a la gonadotropinas, modula la producción de andrógenos por las células de la teca y la producción de progesterona por las células de la granulosa (Cárdenas et al., 2001).

Salvo lo citado existe muy poca información sobre $\mathrm{RE}-\beta$ en ovinos prepúberes.

De esta manera, el propósito de este trabajo fue evaluar la presencia de RE- $\beta$ en los distintos tipos celulares del ovario ovino prepúber mediante análisis inmunohistoquímico.

\section{MATERIAL Y MÉTODO}

Se utilizaron 8 ovejas prepúberes de raza Criollas Araucana de 4 meses de edad mantenidas hasta su sacrificio, en el Campo Experimental Maquehue de La Universidad de La Frontera, de acuerdo con el consentimiento del Comité de Ética de la Universidad. Luego del sacrificio por aplicación de pentobarbital sódico (100 a $200 \mathrm{mg} / \mathrm{Kg}$ ) vía intravenosa (Gnanalingham et al., 2005), se extrajo el útero y se diseccionaron ambos ovarios, los cuales fueron fijados en formalina al 10\% tamponada a $\mathrm{pH} 7,0$ con buffer de fosfatos por $24 \mathrm{~h}$. Las muestras fijadas se procesaron para su inclusión en Paraplast Plus (Mc Cormick Scientific, USA) y posteriormente obtener cortes de $5 \mu \mathrm{m}$, los que fueron montados en portaobjetos para el estudio inmunohistoquímico.
Para la detección inmunogénica, se utilizó el anticuerpos policlonal anti-RE- $\beta$ (H-244, Santa Cruz Biotechnology, USA) diluido 1:500 en tampón fosfato salino e incubando los cortes por 12 horas a $37^{\circ} \mathrm{C}$. Posteriormente, se utilizo el sistema de detección inmunohistoquímica Dako, USA Kit R.T.U Vectastain Universal Elite ABC Kit, $\mathrm{N}^{\circ}$ Cat. PK-7200 (Vector Laboratories, USA) de acuerdo a las instrucciones del fabricante.

\section{RESULTADOS}

Los resultados muestran expresión inmunohistoquímica del receptor de estrógeno beta en diferentes poblaciones celulares ováricas. Principalmente, se observa una destacada señal inmunoreactiva en células del epitelio de revestimiento (Fig. 1) y la granulosa en folículos primarios y secundarios (Figs. 2 y 3 ). También se evidencia señal en células del estroma ovárico pero con menos intensidad (Fig. 4).

\section{DISCUSIÓN}

Los efectos estrogénicos están mediados por receptores de estrógenos, de los cuales se conocen las isoformas alfa $(\mathrm{RE}-\alpha)$ y beta (RE- $\beta$ ). Se tienen evidencias, que el RE $\beta$ media muchas de las acciones de los estrógenos en una gran variedad de tejidos reproductivos incluyendo al ovario

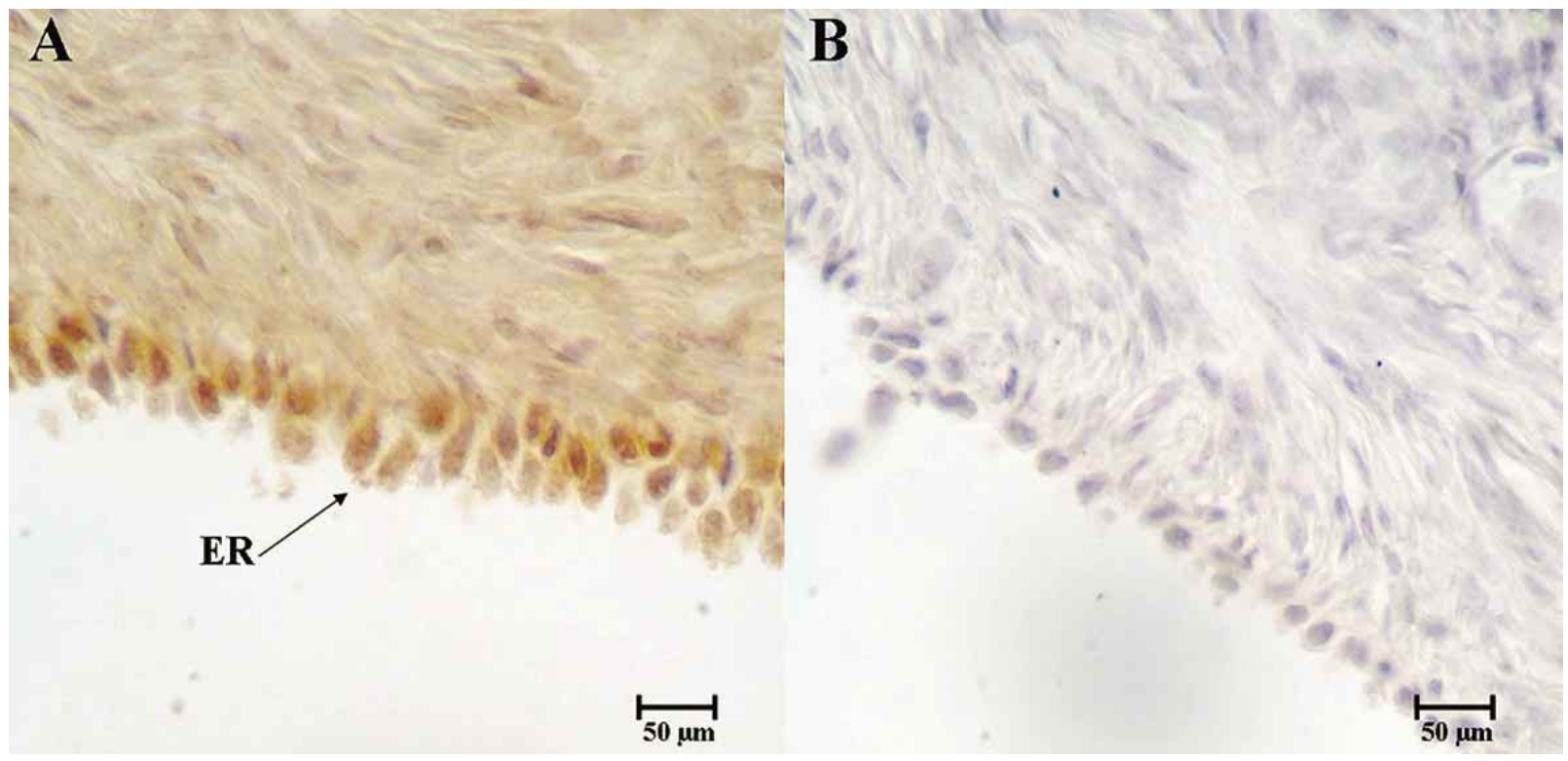

Fig. 1. A. Expresión inmunohistoquímica del RE- $\beta=$ en epitelio de revestimiento ovárico (ER-Flecha), 400x. B. Control negativo, 400X. 


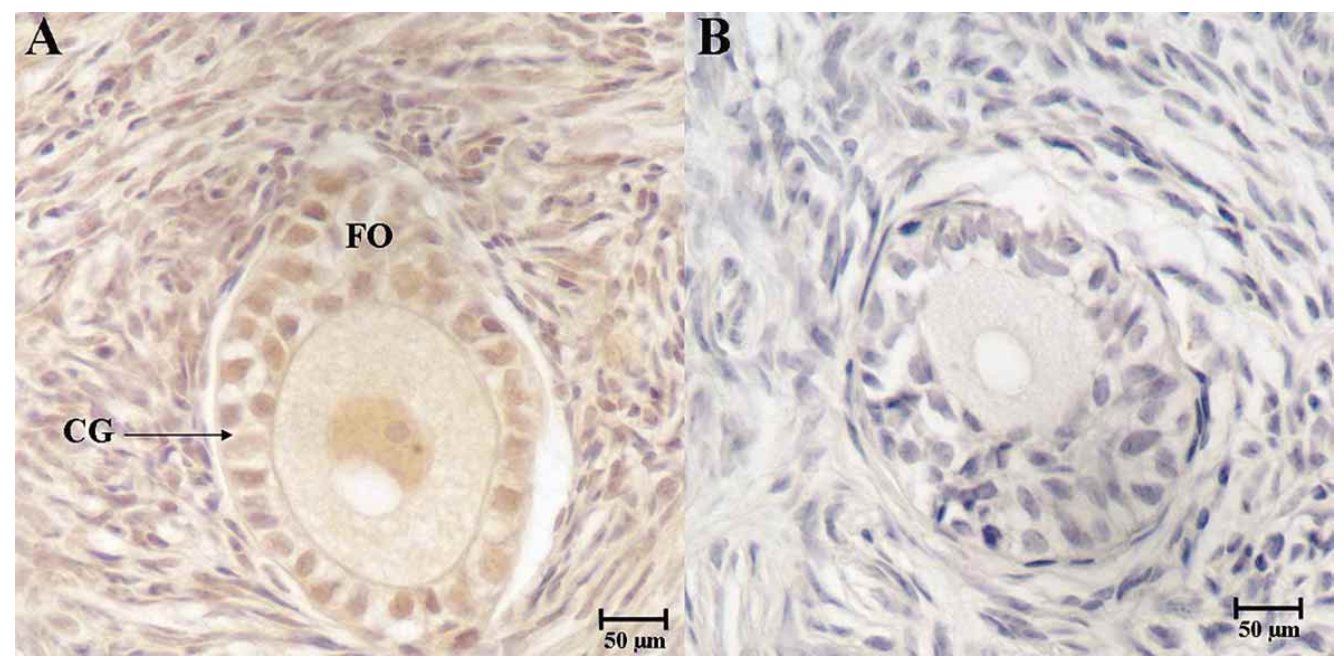

Fig. 2. A. Expresión inmunohistoquímica del RE- $\beta$ en folículo ovárico primario unilaminar (FO), se observa marca inmunoreactiva en células de la granulosa (CG-flecha) y células periféricas estromales, 400X. B. Control negativo, 400X.

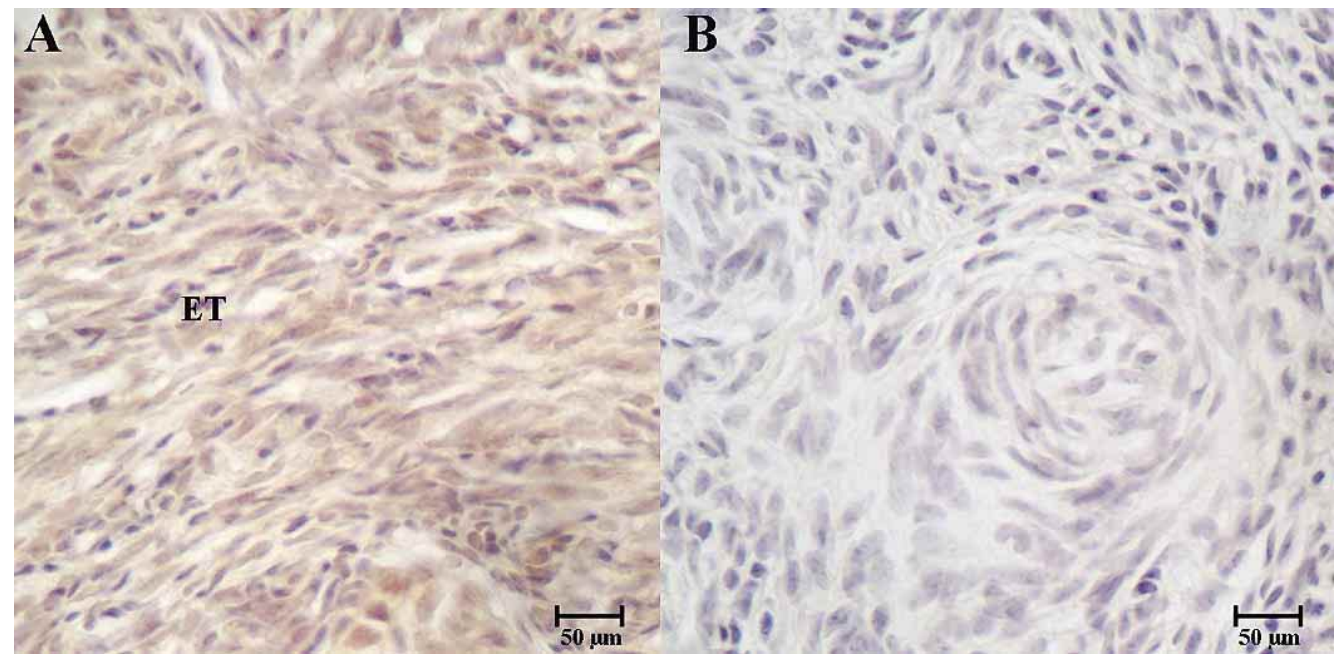

Fig. 3. A. Expresión inmunohistoquímica del RE- $\beta$ en células del estroma ovárico (ET), 400X. B. Control negativo, 400X.

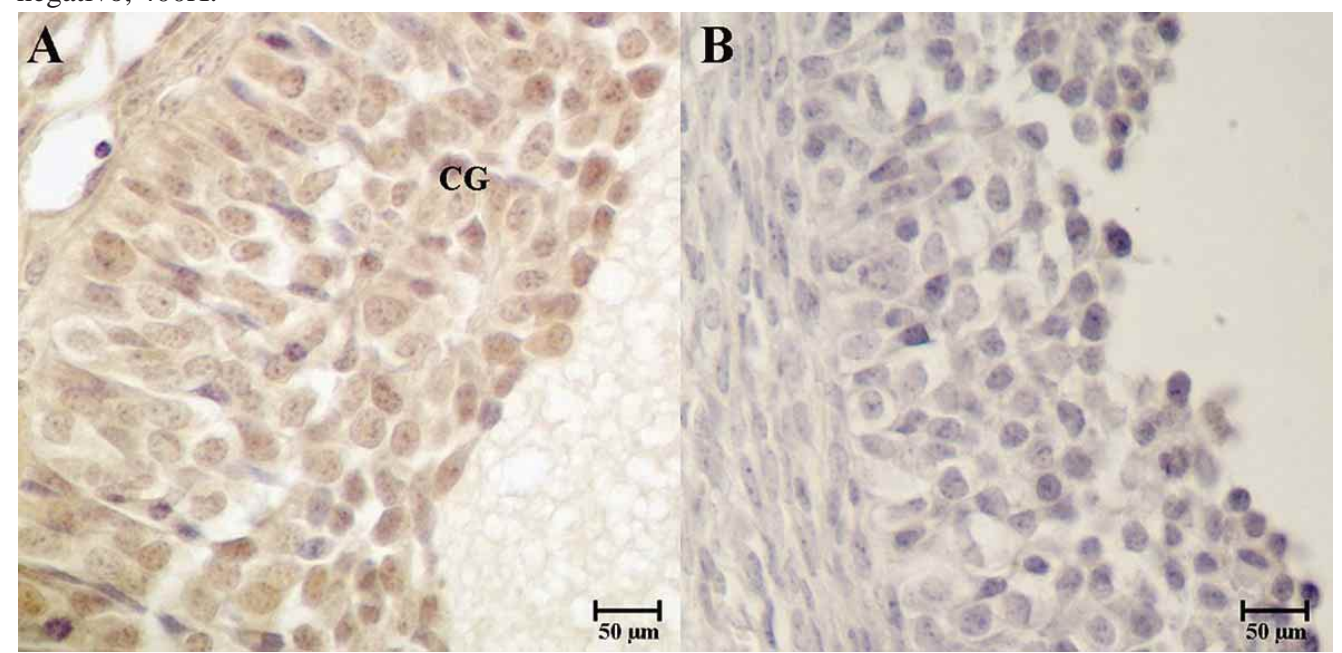

Fig. 4. A. Expresión inmunohistoquímica del RE- $\beta$ en folículo ovárico secundario, se destaca expresión en células de la granulosa (CG) y células tecales (CT), 400X. B. Control negativo, 400X. 
(Meikle et al., 2001; Meikle et al., 2004; Vasconcellos et al., 2014; Vasconcellos et al., 2011).

Autores como Jansen et al. (2001) y Drummond (2006), consideran que el estradiol a nivel ovárico ejerce su efecto mediante su unión a la isoforma beta y que este receptor activado, es el mediador más significativo en la foliculogénesis. Durante el desarrollo distintos tipos celulares del ovario tienen el potencial para responder a los estrógenos y también a los andrógenos.

La expresión de RE- $\beta$ en las células germinales y de la granulosa durante el pico de producción de estradiol es consistente con una función autocrina/paracrina del estrógeno, que activando la vía RE- $\beta$ regula la formación de los ovorígeros y el desarrollo y supervivencia de las células germinales. Estudios en ovejas adultas (Jungel et al., 2006), han demostrado un patrón similar en la expresión de RE- $\beta$ los cuales muestran una significativa expresión en la granulosa y células germinales antes, durante y después de la formación folicular. Se encuentran también en células de la granulosa de folículos preantrales y antrales (Cárdenas et $a l$. .). Esto demuestra el papel fundamental de los estrógenos en la formación y desarrollo de los folículos.
Es posible que una interacción paracrina entre el estradiol y los RE $\alpha$ y RE $\beta$ influya sobre del desarrollo del estroma y de la red vascular del ovario en crecimiento (Britt et al.).

Nuestro estudio demuestra que también el receptor de estrógeno beta se expresa en ovario prepúber ovino destacándose una intensa presencia de él en epitelio de revestimiento y células de la granulosa folicular.

Es posible sugerir que la presencia de receptores beta en ovario prepúber ovino puede estar asociada al control de aspectos de la función ovárica, incluyendo el desarrollo del ovario, la formación de los folículos y el crecimiento folicular temprano. Sin embargo, el papel de los estrógenos en la regulación del crecimiento folicular inicial en prepúberes aún no esta esclarecido.

\section{AGRADECIMIENTOS}

A la Dirección de Investigación de la Universidad de La Frontera, por el apoyo económico entregado mediante el proyecto DIUFRO DI14-01-15

VASCONCEllos, C. A.; PARedes, H. M.; AgUilar, G. C. \& NAVARRETE, V. J. Beta estrogen receptors distribution in the ovary of ewe lambs. Int. J. Morphol., 33(1):388-392, 2015.

SUMMARY: Steroid hormones play an essential role in reproductive physiology, acting in the ovary establishing communication between it and the pituitary gland as well as local paracrine regulators. Described estrogen receptor expression level fetal, neonatal and adult ovaries, which are necessary to determine the cell types that express these receptors. Sheep ovarian stereogenic is active from the fetal stage and therefore steroids play an important role in gonadal development. The regulation of follicle growth is related to several factors on the one hand the secretion of gonadotropins by the pituitary follicular development occurring during late, there was evidence of a direct intra-ovarian estrogen action in the early follicular growth regulation. Our objective was to evaluate the expression and distribution of estrogen receptor $\beta$ in different cell populations of the ovary of prepubertal sheep.

KEY WORDS: Sheep; Ovary; Estrogen Receptor; Araucana breed.

\section{REFERENCIAS BIBLIOGRÁFICAS}

Britt, K. L.; Saunders, P. K.; McPherson, S. J.; Misso, M. L.; Simpson, E. R. \& Findlay, J. K. Estrogen actions on follicle formation and early follicle development. Biol. Reprod., 71(5):1712-23, 2004

Cárdenas, H.; Burke, K. A.; Bigsby, R. M.; Pope, W. F. \& Nephew, K. P. Estrogen receptor beta in the sheep ovary during the estrous cycle and early pregnancy. Biol. Reprod., 65(1):12834,2001

Drummond, A. E. The role of steroids in follicular growth. Reprod. Biol. Endocrinol., 4:16-33, 2006.
Drummond, A. E.; Britt, K. L.; Dyson, M.; Jones, M. E; Kerr, J. B.; O’Donnell, L.; Simpson, E. R. \& Findlay, J. K. Ovarian steroid receptors and their role in ovarian function. Mol. Cell. Endocrinol., 191(1):27-33, 2002.

Evans A. C. Ovarian follicles growth and consequences for ferillity in sheep. Anim. Reprod. Sci., 78(3-4):289-306, 2003.

Gnanalingham, M. G.; Mostyn, A.; Symonds, M. E. \& Stephenson, T. Ontogeny and nutritional programming of adiposity in sheep: potential role of glucocorticoid action and uncoupling protein-2. Am. J. Physiol. Regul. Integr. Comp. Physiol., 289(5):R1407-15, 2005. 
Jansen, H. T.; West, C.; Lehman, M. \& Padmanabhan, V. Ovarian estrogen receptor-beta (ERbeta) regulation: Changes in ERbeta messenger RNA expression prior to ovulation in the ewe. Biol. Reprod., 65(3):866-72, 2001.

Juengel, J. L.; Sawyer, H. R.; Smith, P. R.; Quirke, L. D.; Heath, D. A.; Lun, S.; Wakefield, S. J. \& McNatty, K. P. Origins of follicular cells and ontogeny of steroidogenesis in ovine fetal ovaries. Mol. Cell. Endocrinol., 191(1):1-10, 2002.

Juengel, J. L.; Heath, D. A.; Quirke, L. D. \& McNatty, K. P. Oestrogen receptor a and $B$, androgen receptor and progesterone receptor mRNA and protein localisation within the developing ovary and in small growing follicles of sheep. Reproduction, 131(1):81-92, 2006.

Koering, M. J.; Danforth, D. R. \& Hodgen, G. D. Early follicle growth in the juvenile macaca monkey ovary: the effects of estrogen priming and follicle-stimulating hormone. Biol. Reprod., 50(3):686-94, 1994.

Mauleon, P.; Bezard, J. \& Terqui, M. Very early and transient 17bestradiol secretion by fetal sheep ovary. In vitro study. Ann. Biol. Anim. Biochim. Biophys., 17:399-401, 1977.

Meikle, A.; Tasende, C.; Sosa, C. \& Garófalo, E. G. The rol of sex steroid receptors in sheep female reproductive physiology. Reprod. Fertil. Dev., 16(4):385-94, 2004.

Meikle, A.; Garófalo, E. G.; Rodriguez-Piñon, M.; Tasende, C. \& Sahlin, L. Regulation by gonadal steroids of estrogen and progesterone receptors along the reproductive tract in female lambs. Acta Vet. Scand., 42(1):161-9, 2001.

Sawyer, H. R.; Smith, P.; Heath, D. A.; Juengel, J. L.; Wakefield, S. J. \& McNatty, K. P Formation of ovarian follicles during fetal development in sheep. Biol. Reprod., 66(4):1134-50, 2002.

Vasconcellos, A.; Cisternas, C. \& Paredes, M. Comparative Inmunohistochemical Study of Estrogen Receptor in Endometrial Tissue from Texel and Araucana Sheeps. Int. J. Morphol., 32(3):1120-4, 2014.

Vasconcellos, A.; Paredes, M.; Hernández, C.; Nuñez, D. \& Navarrete, J. Expression of Estrogen and Progesterone Receptors in the Genital Tract of Texel Ewes. Int. J. Morphol., 29 (4):1268-73, 2011.
Dirección para Correspondencia:

Marco Paredes $\mathrm{H}$.

Laboratorio de Investigación en Biotecnología Animal

Departamento de Ciencias Básicas

Facultad de Medicina

Universidad de La Frontera

Temuco

CHILE

Email: marco.paredes@ufrontera.cl

Recibido : 12-11-2014

Aceptado: 09-01-2015 